\title{
Formação docente em ambientes virtuais: quando os professores de Biologia aprendem à distância
}

\author{
Teaching training in virtual environments: when biology teachers learn distance
}

\author{
Formación de profesores en entornos virtuales: cuando los profesores de biología \\ aprenden a distancia
}

\author{
Ercules Laurentino Diniz ${ }^{1}$ \\ Giovanna Barroca de Moura ${ }^{2}$ \\ Maria das Graças de Almeida Baptista ${ }^{3}$
}

\begin{abstract}
Resumo
Tendo em vista o processo de expansão da educação a distância no campo da formação de professores, o presente artigo tem como objetivo principal investigar a concepção de estudantes da Licenciatura em Ciências Biológicas a Distância da Universidade Federal da Paraíba a respeito dos ambientes virtuais de aprendizagem no processo de formação docente. Para tanto, foram realizadas entrevistas com cinco estudantes em formação, sendo as suas concepções analisadas sob o olhar da dialética materialista. Adotou-se esse referencial teórico-metodológico a fim de que fosse possível analisar todas as contradições inerentes a tal formação, a partir do qual foi possível perceber que os estudantes ressaltam a importância do curso a distância como único meio para concretização do sonho de uma formação em nível superior; destacam a importância do desenvolvimento da autonomia para obter êxito ao longo da graduação e asseguram que o curso em questão forma professores de igual modo qualificados quando comparados aos oriundos das licenciaturas nos moldes presenciais.
\end{abstract}

Palavras-chave: Educação a distância; Formação de professores; Ambientes virtuais.

\begin{abstract}
In view of the expansion process of distance education in the field of teacher education, the main objective of this article is to investigate the conception of undergraduate students in Biological Sciences at Distance at the Federal University of Paraíba regarding virtual learning environments in Brazil. teacher training process. To this end, interviews were conducted with five students in training, and their conceptions were analyzed from the perspective of materialist dialectics. This theoretical-methodological framework was adopted so that it was possible to analyze all the contradictions inherent to such training, from which it was possible to perceive that students emphasize the importance of the distance course as the only means to achieve the dream of a higher education; highlight the importance of developing autonomy to be successful throughout the undergraduate course and ensure that the course in question
\end{abstract}

\footnotetext{
${ }^{1}$ Mestre pelo Programa de Pós-Graduação em Educação da Universidade Federal da Paraíba. Professor de Biologia na Rede Estadual de Ensino da Paraíba. Email: ercules.diniz@hotmail.com. ORCID: https://orcid.org/0000-0003-4932-8915.

${ }^{2}$ Mestra em Cooperación al Desarrollo pela Universitat de València, UV, Espanha. Universidade Estadual Vale do Acaraú (UVA). Email: giovannabarroca@gmail.com ORCID: https://orcid.org/0000-0001-7970-432

${ }^{3}$ Pós-doutora em Educação pela Universidade Estadual de Campinas. Professora Associada de Psicologia da Educação do centro de Educação da Universidade Federal da Paraíba. Email: mgabaptista2@yahoo.com.br ORCID: https://orcid.org/0000-0003-1084-4269.
} 
trains equally qualified teachers when compared to those coming from undergraduate courses in the face-to-face model.

Keywords: Distance education; Teacher training; Virtual environments.

\section{Resumen}

En vista del proceso de expansión de la educación a distancia en el campo de la formación docente, el objetivo principal de este artículo es investigar la concepción de los estudiantes de pregrado en Ciencias Biológicas a Distancia de la Universidad Federal de Paraíba sobre los entornos virtuales de aprendizaje en Brasil. proceso. Para ello, se realizaron entrevistas a cinco estudiantes en formación y se analizaron sus concepciones desde la perspectiva de la dialéctica materialista. Este marco teórico-metodológico fue adoptado para que fuera posible analizar todas las contradicciones inherentes a dicha formación, a partir de lo cual se pudo percibir que los estudiantes enfatizan la importancia del curso a distancia como la única forma de realizar el sueño de una educación superior. ; resaltar la importancia de desarrollar la autonomía para tener éxito a lo largo de la carrera de grado y asegurar que la carrera en cuestión capacite a docentes igualmente calificados en comparación con los que vienen de carreras de grado en el modelo presencial.

Palabras claves: Educación a distancia; Formación de profesores; Entornos virtuales.

\section{Introdução}

O crescente avanço da educação a distância é um fenômeno que tem chamado a atenção dos pesquisadores brasileiros. São várias as instituições, públicas ou privadas, que utilizam tal modalidade com o objetivo de democratizar o acesso aos mais variados públicos, sejam eles estudantes egressos do ensino médio que não tiveram oportunidade de cursar uma graduação presencial logo após a conclusão dessa etapa; profissionais em formação continuada; ou estudantes residentes em cidades afastadas dos grandes centros universitários (PEREIRA, 2015).

Em se tratando de ambientes virtuais, acredita-se que o Moodle seja a plataforma mais utilizada em cursos a distância (ALMEIDA, 2020). Trata-se de um espaço que permite discussões de forma assíncrona por meio dos fóruns, ou seja, sem que os indivíduos estejam todos on-line simultaneamente, mas também possibilita discussões síncronas por meio de chats, nos quais os participantes estão todos on-line ao mesmo tempo.

Também existe a possibilidade de que textos sejam escritos de forma colaborativa por meio de Wikis, e os alunos podem enviar suas tarefas para que elas sejam corrigidas com o devido feedback. Questionários, enquetes, envio de textos ou mesmo vídeos, são algumas das possibilidades a serem trabalhadas em cursos que utilizem o Moodle como suporte. 


\section{OO DEVIR EDUCAÇÃO}

ISSN: 2526-849X

Tais ambientes virtuais valorizam o relacionamento estudante-tutor-professor, assim como a relação estudante-estudante, estimulando o desenvolvimento do que se conhece hoje por aprendizagem colaborativa, experiência facilmente vivenciada pelos atores que exploram as plataformas (CORTELINI; DA ROSA, 2020).

Seja qual for o ambiente virtual de aprendizagem, é sempre bom lembrar que alguns atores estão sempre presentes neste processo. A figura do administrador, responsável pela parte técnica; o professor, obviamente, responsável pela condução da disciplina; e o tutor, sem o qual a educação a distância não ocorre com tanta viabilidade.

O tutor, a quem cabe a responsabilidade de "mediar a participação dos estudantes nos chats, estimulá-los a participar e a cumprir suas tarefas, e avaliar a participação de cada um" (GONZALEZ, p.44, 2015) é a ponte entre o estudante e o professor, levando a este as dúvidas e inquietações dos alunos. O tutor também funciona como meio para que o discente possa entender o que está estudando e, principalmente, como mediador entre o estudante e o ambiente virtual de aprendizagem.

Os anos de 1939 e 1941 são muito importantes para tratarmos de exemplos práticos de desenvolvimento de cursos a distância no Brasil, isto porque marcam a criação do Instituto Monitor e do Instituto Universal Brasileiro, respectivamente. O surgimento de ambos é relatado em Alves (2011, p.88), que explicita que o primeiro oferecia "sistematicamente cursos profissionalizantes a distância por correspondência", sendo ressaltado o seu pioneirismo na área; e o segundo, com igual relevância, também foi responsável pela formação de um bom número de profissionais.

Para comprovar a eficiência desses institutos e o comprometimento envolvido em sua idealização, ainda hoje é possível acessar ambos por meio de suas páginas na internet. Passadas algumas décadas, os dois institutos se modernizaram e continuam tendo um bom número de matriculados.

Em um contexto mundial, Peters (2001) apresenta a ideia das Universidades Abertas, instituições que não conceberam a modalidade a distância apenas como uma forma de apoio ao ensino presencial; pelo contrário, enxergam-na com autonomia suficiente para ser oferecida de forma exclusiva. $\mathrm{O}$ autor apresenta exemplos reais desses tipos de instituições, a começar pela Universidade da África do Sul que, "antes de 1970, era a única universidade a distância autônoma no mundo inteiro" (p. 280), tal pioneirismo tem íntima relação com o fato de a instalação ocorrer em um país onde o acesso à educação presencial não é tão disseminado, de modo que o ensino é realizado por meio de correspondências. 


\section{OO DEVIR EDUCAÇÃO}

ISSN: 2526-849X

A modalidade em questão tem sido fundamental para um processo abordado por De Bastiani e Arbage (2018, p.142) que, ao desenvolverem um estudo acerca da expansão do acesso à educação superior, lembram que tal democratização "cumpre um papel relevante quanto à justiça social", uma vez que ingressar em uma instituição de ensino superior ainda representa para muitos brasileiros a única opção perante o horizonte da mobilidade social.

Muitos estudos acerca da Educação a distância refletem a respeito dos materiais adotados nesses cursos, das plataformas utilizadas, no material humano que torna possível a realização dessas graduações, como é o caso dos trabalhos de Paião e Paião (2016), mas estes não parecem dar ouvidos aos principais atores desse processo, a saber, os estudantes. Como resultados desses estudos, são apontados avanços, mas também muitos desafios. No entanto, o que chama atenção é que a solução para os problemas da educação a distância não parecem estar nas mãos dos pesquisadores que sobre ela refletem, até mesmo pelo fato de muitos deles não terem a experiência em ambientes virtuais na condição de aprendizes. Sendo assim, ouvir os estudantes que estão diretamente envolvidos no processo de ensino-aprendizagem a distância talvez seja a maneira de obter informações valiosas que nos levarão a uma melhor compreensão da modalidade em questão.

Sendo assim, a análise da concepção discente transforma-se em ferramenta importante no processo de compreensão do fenômeno da aprendizagem a partir dos ambientes virtuais. Dessa forma, o presente artigo tem por objetivo principal investigar a concepção de estudantes da Licenciatura em Ciências Biológicas a Distância da Universidade Federal da Paraíba a respeito dos ambientes virtuais de aprendizagem no processo de formação docente.

Considerando-se escassos os estudos acerca do tema observado a partir do materialismo histórico dialético, este se apresenta como fundamentação teórico-metodológica para a pesquisa em questão, uma vez que permite ao pesquisador, entre outras ações, debruçar-se sobre as contradições envolvidas no fenômeno, visando sair da aparência para a essência.

\section{Aspectos Metodológicos}

Quanto à metodologia da pesquisa, utilizou-se uma entrevista semiestruturada a fim de obter as informações da amostra de 5 (cinco) estudantes do curso de Licenciatura em Ciências Biológicas da UFPB Virtual distribuídos pelos Polos de apoio presencial, estando quatro desses sujeitos ainda em formação e um já desempenhando a função docente. A escolha de 


\section{OO DEVIR EDUCAÇÃO}

ISSN: 2526-849X

cinco participantes é justificada pela disponibilidade, tendo em vista os obstáculos impostos pelas distâncias geográficas, também se deve ao fato de acreditarmos que as relações se efetivam "sempre no interior de relações concretas com outros indivíduos" (DUARTE, 2011. p.147), sendo assim, independente de quantos sujeitos participam, cada um apresenta uma contribuição significativa que representa a síntese de todas essas relações vivenciadas ao longo de sua formação. As questões lançadas aos participantes foram as seguintes: 1. O que o levou a fazer uma graduação a distância? 2.Como é ser um aluno(a) de um curso a distância? 3. Na sua opinião, é possível aprender a partir dos ambientes virtuais? 4. O que a plataforma representa para o seu aprendizado? Nas respostas dos sujeitos, encontramos algumas as categorias relevantes para a nossa análise, a exemplo de aprendizagem virtual.

Assim, considerando que os Polos estão distribuídos por diversas regiões da Paraíba, foram escolhidos dois estudantes de um Polo mais próximo à capital João Pessoa; dois estudantes de outro Polo localizado no sertão paraibano; assim como um ex-estudante do curso que, atualmente, exerce a docência de forma presencial em uma cidade situada no agreste paraibano. A escolha deste último foi feita por entendermos que tal sujeito faria importantes reflexões acerca do caminho entre a formação à distância e a prática presencial. As entrevistas ocorreram de forma presencial por meio do encontro com os estudantes nos respectivos polos de apoio presenciais (à época, não estávamos em pandemia), sendo gravadas e devidamente transcritas pelo pesquisador. É importante ressaltar que a pesquisa recebeu parecer favorável do comitê de ética, uma vez que atende às resoluções nº466/12 e nº510/2016 do Conselho Nacional de Saúde.

Baseado no materialismo histórico e dialético, o pesquisador compreende que a teoria, como afirma Netto (2011, p. 21), "é o movimento real do objeto transposto para o cérebro do pesquisador", levando-se em consideração a anterioridade da matéria em relação à ideia. É interessante observar que, segundo Lessa (2011, p. 41), "para Marx, o mundo dos homens nem é pura ideia nem só matéria, mas sim uma síntese de ideia e matéria que apenas poderia existir a partir da transformação da realidade", o que demonstra o caráter histórico de tal fundamentação, que consiste em acreditar na possibilidade de mudança do estágio atual.

Ao abordarem três diferentes modelos teóricos que versam sobre a relação sujeitoobjeto, Ghedin e Franco (2011) afirmam que, enquanto o modelo objetivista valoriza a exterioridade da realidade, o modelo subjetivista enfatiza a subjetividade do pesquisador. $\mathrm{Na}$ perspectiva dialética não há separação entre sujeito e objeto, sendo a realidade construída pelos homens historicamente, a partir das múltiplas determinações. 
Para análise geral do que fora extraído das falas dos sujeitos, optamos pela união entre a hermenêutica e a dialética, isso porque concordamos com Minayo (1996, p.227) quando ela reforça a ideia de que "ambas partem do pressuposto de que não há observador imparcial nem há ponto de vista fora do homem e fora da história”, visão que, no nosso entender, tem íntima relação com a fundamentação teórico-metodológica escolhida para o presente estudo.

\section{Aprendizagem virtual $\mathrm{x}$ aprendizagem presencial: uma contradição real?}

Em relação à aprendizagem virtual no âmbito dos cursos a distância, percebe-se que uma discussão é estabelecida em torno da possibilidade de aprender a partir da utilização de ambientes virtuais, seja ele o Moodle ou outro que tenha a mesma finalidade. O fato é que há uma desconfiança no tocante às plataformas em questão, tanto por parte dos professores, quanto dos estudantes de cursos presenciais e, por que não dizer, de grande parte da sociedade (RICARDO, 2018).

Essa dúvida a respeito da confiabilidade da EaD acontece porque, habituados ao cotidiano de estudar em salas de aula físicas, em escolas com estruturas que, até pelo senso comum, são percebidas como capazes de viabilizar um processo de ensino-aprendizagem significativo, não acreditam ser possível, entre outros aspectos, aprender sem a presença direta de um professor.

Com relação aos participantes deste estudo, quando perguntados sobre a efetividade do ensino a partir dos ambientes virtuais, os estudantes demonstraram acreditar na utilização de plataformas, a exemplo do Moodle, enquanto forma legítima de tornar possível a aprendizagem em cursos a distância.

A esse respeito, o estudante A afirma: "Com certeza, além de ser mais desafiador que o presencial, eu acho, no meu ponto de vista. Assim, você é induzido a pesquisar mais, você é induzido a pesquisar". Para ele, não somente é possível, como é mais instigante, e acredita que é exigida uma permanente presença na plataforma, algo que, ao seu modo de ver, não ocorre com o estudante de curso presencial, porque este pode restringir todo seu horário de estudo aos momentos em que se encontra em sala de aula física.

O estudante B considera que "o Moodle é uma porta aberta, uma sala de aula perfeita para o aluno aprender" e também acredita que o aluno do curso a distância é até mesmo mais cobrado do que nos cursos presenciais. Isso se deve ao fato de que, durante todas as semanas, 
os estudantes são constantemente submetidos às avaliações no ambiente virtual, seja por meio de fóruns, questionários ou qualquer outro tipo de atividade.

É possível observar que as comparações entre o curso presencial e a distância estão sempre presentes nas falas deles, sendo a segunda modalidade, na maioria das vezes, tida como mais desafiadora. Podemos depreender, portanto, que os estudantes em questão precisam de forma recorrente reafirmarem a importância da graduação em que estão matriculados, uma vez que sempre são alvos de comparação com os estudantes de cursos presenciais.

O preconceito em torno da modalidade também é citado por todos eles, e percebe-se que se deve ao fato de grande parte da sociedade não acreditar que os cursos a distância sejam capazes de propiciar capacitação adequada aos profissionais em formação. A respeito disso, o estudante $\mathbf{A}$ afirma que:

No começo do curso a gente debatia isso aqui e, assim, muitos diziam que o pessoal do presencial via os do virtual como "ah, esse aí não sabe nada" - aquela coisa -, acho totalmente equivocada a parte deles pensar assim, que nós do virtual não vamos saber, porque aprende e aprende até melhor se brincar, depende do interesse de cada um, no meu ponto de vista. (EA)

Nesse sentido, pelo menos dois aspectos merecem destaque. O primeiro diz respeito ao conflito "presencial x virtual”, marcado pelo juízo aceito e pactuado pela sociedade, a saber: “o curso presencial é melhor que o curso a distância". Tal afirmação revela um raciocínio do senso comum, que se configura como um equívoco e deve-se ao pouco conhecimento no que se refere à modalidade e, até certo ponto, ao fato do estudante presencial desejar ter seus privilégios garantidos e exclusivos. O segundo aspecto relevante diz respeito à dedicação de cada estudante. $\mathrm{O}$ fato de relacioná-la ao sucesso da aprendizagem a distância aponta que a própria opção por um curso nesses moldes já se encontra marcada pelo interesse de alguém que não teve a oportunidade de matricular-se, frequentar e concluir um curso presencial.

Ainda a respeito, o estudante $\mathrm{E}$, único dos entrevistados que já concluiu o curso, demonstra que enfrenta o preconceito em torno da modalidade:

Eu encarei da seguinte maneira: mostrando o meu conhecimento, mostrando que eu sou capaz. O exemplo está aí, eu passei no mestrado, a minha colocação foi $5^{\circ}$ lugar. Eu não quis bolsa pra não me estressar, ter que ir daqui pra João Pessoa, levar documento. Realmente vale a pena fazer o curso a distância, agora quem faz é o aluno, não é o professor não, é a equipe, o conjunto. (EE) 
Percebe-se, no caso desse sujeito, que mesmo ele sendo, atualmente, professor concursado da educação básica e estudante de mestrado, sente a necessidade de auto afirmarse como capaz, mediante as críticas advindas de outros professores formados na modalidade presencial e que não acreditam na educação a distância. Outro ponto importante que este estudante traz é a relevância da equipe, do conjunto, sendo indicados como fatores indispensáveis à continuidade do processo de ensino-aprendizagem em uma graduação a distância.

Os próprios estudantes apontam que a plataforma utilizada de forma isolada não possibilita o conhecimento necessário para obtenção de um aprendizado sólido, a exemplo do estudante $\mathbf{E}$, ao sinalizar que "tem que buscar outras fontes, outros recursos. Revista, livro, a própria internet, vídeo, no youtube têm videoaulas muito boas". Assim como a estudante D, ao afirmar que a plataforma:

\footnotetext{
Representa acho que... $70 \%$ do meu aprendizado, porque eu também tenho pesquisas fora da plataforma que é importante a gente ter outros pontos de vista, mas a plataforma representa basicamente uns $70 \%$, porque o professor nos dá o ponto de partida e até mais da metade, mas a plataforma em si, ela é muito boa, eu gosto bastante. (ED)
}

Acreditamos que tamanha importância dada à plataforma tem íntima relação com o desenvolvimento da autonomia do estudante. Considerá-la como grande responsável por seu aprendizado é, de certa forma, compreender-se como um sujeito capaz de trilhar os caminhos sem o auxílio do professor. O desenvolvimento da autonomia do estudante deve sempre ser levado em consideração, cabendo ao professor dar liberdade aos discentes para explorar o território do curso (PALLOFF; PRATT, 2004, p.15) e outros ambientes virtuais.

\section{Mediação pedagógica a distância x Mediação pedagógica presencial}

A palavra mediação remete à ponte, interlocução entre sujeitos, ligação entre lugares ou pessoas. Ao referir-se, portanto, à mediação pedagógica, ressaltam-se as conexões que existem para propiciar o processo de ensino-aprendizagem e os contatos estabelecidos entre os sujeitos participantes de tal processo (CAVALCANTI, 2005).

Obviamente, ao falarmos da aprendizagem virtual, tais pontes devem estar estabelecidas entre os seguintes pares: "professor-estudante"; "estudante-ambiente"; "estudante-estudante", de forma que se construam caminhos que propiciem um processo 
pedagógico exitoso. É importante ressaltar que essas pontes também são construídas com relação ao conteúdo, estando esse disponível, de forma majoritária, na plataforma.

O potencial pedagógico dos ambientes virtuais é tão significativo que, a partir das falas dos sujeitos entrevistados, é possível ter o entendimento que o ambiente virtual não é só um meio para se chegar ao aprendizado, mas torna-se o próprio professor, ou seja, se este é relapso e não cumpre o seu papel, o processo de ensino-aprendizagem, embora afetado, não deixa de ocorrer.

É nesse sentido que o estudante $\mathbf{E}$ ressalta a necessidade de ser autônomo na construção de sua própria aprendizagem, bem como perceber os colegas como participantes importantes nesse processo:

Então, o curso a distância quando a gente quer, aprende, tem que adquirir autonomia pra aprender, isso é importante também dentro do curso e a gente só adquire autonomia se for buscar, ler, perguntar, através de atividade de grupo também que ajuda bastante. (EE)

Os estudantes ratificam a possibilidade de aprender colaborativamente, sendo o caso do estudante $\mathbf{B}$ que, ao afirmar que "aprendia muito, têm uns alunos daqui que têm um nível muito bom, eu aprendi muito com eles", entende a importância dos seus colegas para a construção do próprio aprendizado. Nesse sentido, é interessante ressaltar que essa colaboração vai para além do aspecto conteudista, ou seja, os colegas não representam apenas mediadores que os levam à aprendizagem sobre determinado assunto, mas incentivadores que constituem fator determinante para continuidade do curso.

Posto isso, observemos as falas dos estudantes $\mathbf{B}$ e $\mathbf{C}$, respectivamente:

Já pensei em desistir várias vezes, onde muitos colegas aí do curso me incentivaram, vou desistir não, vou continuar, mas foi graças a eles e a alguns tutores que eu continuei e tô até hoje no curso. (EB)

Continuo, eu até já pensei em desistir do curso, mas tive o apoio dos colegas que é fundamental, assim, a comunicação da gente é por telefone, via whatsapp. (EC)

Ambos apontam o auxílio dos colegas como imprescindível para a permanência do curso, algo que deve ser considerado, pois os índices de evasão em cursos a distância ainda permanecem altos. Seja por telefone, mensagens de texto ou recursos presentes na própria plataforma, os estudantes, a partir de suas experiências, contribuem de forma significativa para o sucesso mútuo. 
Toda essa motivação é ainda mais relevante quando observamos as histórias dos sujeitos em questão. Somado ao fato de estarem distantes dos grandes centros universitários, o tempo decorrido entre a formação básica e o ensino superior também constitui um importante elemento para a nossa reflexão. Nesse sentido, vejamos o que apontam os estudantes $\mathbf{B}, \mathbf{C}$ e E, respectivamente:

Não, eu não tinha interesse em fazer nenhum curso superior. Foi meus parentes, minha família que praticamente me obrigou a voltar a estudar. Fazia 10 anos que eu estava parado. (EB)

Eu queria muito, logo após ter finalizado o ensino médio, eu queria muito entrar pra Universidade, não consegui nenhuma presencialmente no ano seguinte, mas consegui a EAD. (EC)

Tenho 53 anos e sou natural de Solânea. Universidades são distantes, eu trabalho, já trabalhava na época e não tinha como conciliar o curso presencial com o trabalho, surgiu essa oportunidade do curso de Ciências Biológicas a Distância pela UAB e eu aproveitei, fiz vestibular. (EE)

Seja o longo espaço de tempo longe dos estudos, a falta de instituição de ensino superior, ou a impossibilidade de conciliação entre trabalho e estudos, o fato é que todos constituem obstáculos que podem implicar em dificuldades significativas no processo de ensino-aprendizagem de tais estudantes. O professor que ignora tais eventualidades e que se constitui "mediador" apenas entre o estudante e o conteúdo, compreendendo o indivíduo em sua acepção imediata, assim, perde uma excelente oportunidade de utilizar a educação como ferramenta que prepare tal sujeito para viver na chamada "Sociedade do Conhecimento".

\section{Formação de professores a distância $x$ formação de professores presencial}

Ao refletirem acerca da importância de compreendermos o fenômeno educativo do ponto de visto do cuidado com os outros, Kuhn e Callai (2020, p.16) nos lembram que "a formação de professores e a docência requerem mais do que apenas conhecimentos e saberes instrumentais", sendo necessário romper com a racionalidade técnica no processo de formação docente. Talvez seja nesse ponto em que a educação a distância apresente as maiores limitações quando voltada à capacitação de professores, pois ainda está muito atrelada aos recursos tecnológicos.

Ainda assim, é no campo da formação de professores que a educação a distância ganha significativa notoriedade em nosso país (ARRUDA, 2018). A importância da EAD para essa formação precisa ser considerada a despeito de todas as contradições envolvidas nesse 
processo, posto que tal fenômeno ainda constitui uma das maiores limitações às políticas educacionais.

Nesse aspecto, as falas dos entrevistados possibilitam compreender tal avanço, ainda que seja inevitável para eles estabelecer comparações com o ensino presencial. Residindo em cidades sem a presença de Instituições de Ensino Superior, a Licenciatura em Ciências Biológicas a distância representou a única possibilidade de acesso a uma graduação.

O estudante $\mathbf{B}$, mesmo tendo que enfrentar alguns percalços pelo fato de não residir na mesma cidade do polo no qual está matriculado - "Quando não tenho carona eu acordo 5 h30 da manhã, o ónibus sai de 6 de Pedras de Fogo, chega 7 h na entrada do Conde, aí eu pego outro transporte." -, sente-se muito bem atendido pelo curso em questão. O mesmo ocorre com o estudante $\mathbf{C}$, que salienta a importância da graduação a distância para sua formação:

\footnotetext{
"Eu queria muito, logo após ter finalizado o ensino médio, eu queria muito entrar pra Universidade, não consegui nenhuma presencialmente no ano seguinte, mas consegui a EAD aqui, aí vim pra cá e é um curso que eu gosto muito, Ciências Biológicas." (EC)
}

A educação a distância, nesse sentido, cumpre um papel em duas vertentes: possibilitar o acesso ao ensino superior a estudantes de cidades do interior, neste caso, os municípios do Conde e de São Bento, situadas no litoral e sertão da Paraíba, respectivamente; e na formação de professores que podem, ao concluírem o curso, exercer suas atividades no próprio município em que residem, como ocorre com grande parte dos estudantes egressos da licenciatura em questão.

Quando perguntados se estariam aptos a exercerem a função docente de forma presencial, mesmo sendo graduados em um curso a distância, os estudantes asseguram confiar na sua formação, como no caso dos estudantes $\mathbf{B}$ e $\mathbf{C}$, respectivamente:

\footnotetext{
"Eu acho que estou pronto, o professor não sai da Universidade 100\% só que ele sai com a mentalidade, eu vou dar aula de biologia celular, mesmo sabendo muito eu tenho que ler mais, se aprofundar mais, porque a biologia, ela muda, os conceitos mudam." (EB)

"Eu me vejo preparada, porque tudo que um aluno de uma Universidade presencial viu eu também vi, então, não tem diferença entre a gente, nenhuma, então, tudo que ele pode ensinar, eu também posso, porque eu aprendi." (EC)
}

Tal confiança deve-se ao fato de compreenderem que a Universidade Federal da Paraíba preza pela rigorosidade acadêmica tanto dos cursos presenciais, como daqueles 
desenvolvidos na modalidade a distância. Os professores são os mesmos, os tutores são preparados e os diplomas são reconhecidos pelo MEC. Os alunos também sinalizam que o comportamento que terão no exercício da docência é o mesmo de um professor oriundo do curso presencial, e que nunca estarão inteiramente prontos somente por terem cursado uma licenciatura, sendo necessário para essa qualificação atualizar-se sempre, utilizando para isso, por exemplo, as formações continuadas, as quais têm ocorrido majoritariamente na modalidade a distância.

Sendo essas exigências postas ao professor atualmente, entende-se que os estudantes formados a partir de uma modalidade a distância, onde o contato com os ambientes virtuais é constante, podem obter vantagem no processo de adaptação às novas demandas. Sabemos que, hoje em dia, o professor deve estar atento e preparado para as novidades virtuais que fazem parte do universo dos estudantes.

Dessa forma, é preciso assegurar, ao longo do processo formativo, variáveis que, segundo os autores especializados em Educação a Distância, são imprescindíveis em cursos que ocorrem nesses moldes. Moore (2013) afirma que diálogo e estrutura são fundamentais para que estejam garantidos os níveis de interação necessários, em concordância com Kearsley (2011, p.81), que ressalta a importância de, em classes on-line, o professor “assegurar alto grau de interatividade e participação". Nicolodi (2013, p.58) aponta o quanto a mediação pedagógica em cursos a distância "permite a interlocução horizontalizada entre alunos e professores".

\section{Considerações Finais}

A tradição nos leva a perceber a configuração escolar como único espaço propício à aprendizagem formal. Kruppa (1994, p. 30) aponta que esse ponto talvez seja o que mais reforça esse argumento: “a escola tem horário, estabelece critérios para o agrupamento dos alunos, tem profissionais executando papéis diferenciados...”. Ou seja, é essa organização, não encontrada em ambientes virtuais, ou sendo desenvolvida de outras maneiras, que leva o espaço físico da escola a ser considerado próprio para o desenvolvimento do processo de ensino-aprendizagem e, certamente, essa noção é estendida para o ambiente universitário. Mas Kenski (2012, p. 116) nos adverte quando afirma que "as competências e habilidades dos alunos da geração net estão mudando. O movimento vem de fora das escolas e é ela que, cada vez mais, sofrerá suas consequências", assim, é nesse contexto que o trabalho em questão 


\section{OO DEVIR EDUCAÇÃO}

ISSN: 2526-849X

destaca a educação a distância como uma alternativa importante para a formação de professores.

A escola, enquanto instituição, estabeleceu-se como uma estrutura tão sólida que não aparenta não poder ser questionada, tampouco ser substituída por outros meios que propiciem a aprendizagem. O ambiente físico é entendido como o único espaço em que o estudante pode acessar o conhecimento, sendo, portanto, compreensível, a ideia compartilhada por grande parte da sociedade de que o estudante só pode aprender de fato se estiver dentro de uma escola, ou, no caso do ensino superior, dentro de uma Universidade na modalidade exclusivamente presencial.

Tal percepção encontra-se equivocada, em primeiro lugar por ignorar os espaços informais de aprendizagem, à exemplo da convivência com a família, de visitas à museus, centros culturais, etc. ; e em segundo lugar, por ser incoerente com o momento em que vivemos em termos de tecnologias digitais. Os atores envolvidos na educação a distância não só precisam se desvencilhar de tais preconceitos, como também devem estar atentos às mudanças em nossa sociedade e acreditar que essa modalidade pode propiciar conhecimento a quem dela usufrua. Compreendemos que, a menos que haja uma mudança de pensamento e de postura, os sujeitos não estarão aptos a exercer seus papéis, tanto os professores e tutores, que tornam possível o processo de ensino-aprendizagem, quanto os estudantes, que aprendem por meio desta modalidade de educação.

Podemos concluir que a educação a distância é, hoje, imprescindível no que se refere à democratização do acesso ao ensino superior. Além disso, é uma modalidade que vem adquirindo cada vez mais espaço no campo da formação de professores. Por isso, os estudantes enxergam nela uma oportunidade única de ingressar no ensino superior e adquirir novos saberes que os habilitarão ao exercício da docência, uma vez que encontram-se afastados dos polos presenciais.

O fato de haver sujeitos envolvidos com a educação a distância que ainda não acreditam ser possível que alguém consiga habilitar-se por meio de cursos nessa modalidade, merece atenção, uma vez que tal afirmação carece de bases científicas. Na contramão dessa opinião, os entrevistados evidenciaram conhecimentos adquiridos durante o curso; mostraram-se familiarizados com termos próprios da educação a distância; falaram com propriedade acerca dos recursos tecnológicos utilizados ao longo do curso; e, principalmente, demonstraram domínio da plataforma Moodle. Além disso, os discentes entrevistados descreveram a experiência virtual como uma efetiva possibilidade de se aprender, 


\section{OO DEVIR EDUCAÇÃO}

ISSN: 2526-849X

considerando os ambientes virtuais como pontes significativas entre eles e o aprendizado que propicia a formação.

A relação dos estudantes com o ambiente virtual é contínua e consiste em um aprendizado diário. Dessa forma, o curso é vivenciado com intensidade e cotidianamente pelos estudantes, uma vez que a plataforma virtual de aprendizagem pode ser acessada a partir de smartphones, computadores e outros suportes digitais. Nicolodi (2013, p. 34) ressalta que "a incorporação das tecnologias digitais na $\mathrm{EaD}$ representa uma mudança paradigmática, na qual o modelo de ensino como transmissão de conhecimento dá lugar ao modelo de aprendizagem como construção de sistemas conceituais", sendo, portanto, o estudante, agente ativo no processo.

Percebe-se que a problemática relacionada à $\mathrm{EaD}$ nem sempre diz respeito à concepção do modelo, mas à forma como este tem sido desenvolvido pelas diversas instituições, havendo, em inúmeras situações, comprometimento da aprendizagem virtual, uma vez que, nem sempre os cursos estão em conformidade com o que preconizam os estudiosos da educação a distância. Allarcon e Spanhol (2017, p.64) nos lembram de que "a qualidade dos serviços de Educação a Distância - EaD depende da realidade e do contexto educacional e organizacional para atender as necessidades culturais, sociais e econômicas do ambiente onde irá atuar", ou seja, é preciso alinhar os cursos às realidades locais, levando em consideração, inclusive, o perfil dos estudantes.

Deve-se também ponderar que, conforme nos alertam Barros e Guerreiro (2019, p.413), a EaD é "um conjunto de elementos (Instituição, Qualidade, Avaliação, Modelo Pedagógico, Infraestruturas, Curso/Currículo, Professor, Tutor, Tecnologias e o Aluno)”, ao contrário dos que compreendem o fazer pedagógico a distância como restrito ao depósito de textos em uma plataforma.

Outro ponto que merece atenção diz respeito ao papel dos professores nesses espaços. Pallof e Pratt (2015) esclarecem que o nosso modelo educacional ainda contribui para a compreensão do professor como a única fonte capaz de proporcionar conhecimento e que em ambientes virtuais essa lógica não pode prevalecer. Ainda nesse sentido, Belloni (2015, p.117) afirma que "as mudanças nas características e estruturas do ensino acarretam necessariamente transformações profundas nas funções dos professores" e, podemos acrescentar, na função dos tutores, sendo estes, como colocado por Lemos e Pasquetto (2019, p.2), "responsáveis por acompanhar a vida acadêmica dos estudantes, apontando caminhos 
para determinados problemas ou propostas", configurando-se como um facilitador do processo de ensino-aprendizagem.

Com a ampliação da $\mathrm{EaD}$, os estudantes poderão explorar cada vez mais o ambiente virtual, que quanto mais amparado estiver, no que se refere às questões específicas da educação a distância, como acesso a internet de qualidade e polos estruturados, melhor exercerá suas funções pedagógicas. Nesse sentido, ouvir atentamente os estudantes torna-se necessário para a elaboração dos cursos, porque a opinião destes funciona como um direcionamento para as políticas que dizem respeito à educação a distância.

Dessa forma, espera-se que novas pesquisas sejam realizadas e que levem em consideração outras amostras, cursos e regiões, a fim de que os resultados aqui encontrados possam ser confirmados, ou mesmo que possam compará-los no que diz respeito à concepção dos ambientes virtuais de aprendizagem e a viabilidade destes no processo de ensinoaprendizagem.

\section{Referências}

ALLARCON, Dafne Fonseca; SPANHOL, Fernando José. O fluxo de conhecimento na produção de ambientes virtuais de aprendizagem. Revista Brasileira de Aprendizagem Aberta e a Distância, São Paulo, v.16, n.1, p. 63-72, 2017. Disponível em: http://seer.abed.net.br/index.php/RBAAD/article/view/282. Acesso em: 22 jun. 2020.

ALMEIDA, Everton Fagner Costa de. Fundamentos da EAD e ambientação virtual. Natal: IFRN, 2020.

ALVES, Lucineia. Educação a distância: Conceitos e história no Brasil e no mundo. Revista Brasileira de Aprendizagem Aberta e a Distância, São Paulo, v. 10, n.1, p. 83-92, mai. 2011. Disponível em: http://seer.abed.net.br/index.php/RBAAD/article/view/235. Acesso em 24 fev. 2021.

ARRUDA, Eucidio Pimenta. Reflexões sobre a política nacional de formação de professores a distância e o enfraquecimento da EaD pública pela Universidade Aberta do Brasil (UAB). Educação (UFSM), Santa Maria, RS, v. 43, n.4, p. 823-842, out/dez. 2018. Disponível em: https://periodicos.ufsm.br/reveducacao/article/view/32607. Acesso em 24 mar.2021.

BARROS, Daniela Melaré Vieira; GUERREIRO, Aníbal Martins. Novos desafios da educação a distância: Programação e uso de Chatbots. Espaço Pedagógico, Passo Fundo, RS. v.26, n.2, p.410 -431, mai. 2019. Disponível em: http://seer.upf.br/index.php/rep/article/view/8743/114114578. Acesso em: 22 jun. 2020.

BELLONI, Maria Luiza. Educação a distância. Campinas: Autores Associados, 2015. 
CAVALCANTI, Lana de Souza. Cotidiano, mediação pedagógica e formação de conceitos: uma contribuição de Vygotsky ao ensino de geografia. Caderno Cedes ‘ Campinas, SP, v. 25, n. 66, p. 185-207, mai/ago. 2005. Disponível em: https://www.scielo.br/pdf/ccedes/v25n66/a04v2566.pdf. Acesso em: 23 mar. 2021.

CORTELINI, Valdete Gusberti; DA ROSA, Geraldo Antônio. Relações construídas no diálogo e na mediação através do pensar: aprendizagem colaborativa na EAD. Revista Linhas, Florianópolis, v,21, n.47, p. 385-404, ago. 2020. Disponível em: https://www.periodicos.udesc.br/index.php/linhas/article/view/13935/12441 Acesso em: 23 mar. 2021.

DE BASTIANI, Sherlon Cristina; ARBAGE, Lucas Andres. As políticas para expansão e democratização do acesso à educação superior no cenário brasileiro. Revista Pedagógica, Chapecó, SC. v.20, n.44, p.137-152, set., 2018. Disponível em: https://bell.unochapeco.edu.br/revistas/index.php/pedagogica/article/view/3673. Acesso em 05 jan.2021.

DUARTE, Newton. Vigotski e o 'aprender a aprender': crítica às apropriações neoliberais e pós-modernas da teoria vigotskiana. 5. ed. Campinas: Autores Associados, 2011.

GHEDIN, Evandro; FRANCO, Maria Amélia Santoro. Questões de método na construção da pesquisa em educação. 2. ed. São Paulo: Cortez, 2011.

GONZALEZ, Mathias. Fundamentos da tutoria em educação a distância. 2.ed. São Paulo: Avercamp, 2015.

KEARSLEY, Greg. Educação on-line: aprendendo e ensinando. São Paulo: Cengage Learning, 2011.

KENSKI, Vani Moreira. Educação e tecnologias: o novo ritmo da informação. Campinas: Papirus, 2012.

KRUPPA, Sônia Maria Portella. Sociologia da Educação. São Paulo: Cortez, 1994.

KUHN, Martin; CALLAI, Helena Copetti. Teoria crítica, hermenêutica e formação de professores: contribuições de Mario Osorio Marques. Revista Pedagógica, Chapecó, SC. v. 22, p. 1-19, abr. 2020. Disponível em < http://pegasus.unochapeco.edu.br/revistas/index.php/pedagogica/article/view/4364> Acesso em 05 jan. 2021.

LEMOS, Suyane Souza; PASQUETTO, Rodrigo Giliardi. Funções dos tutores presenciais na Educação a Distância. Ead em foco, Rio de Janeiro, v.9, n.1, p.1-10, mar. 2019. Disponível em: https://eademfoco.cecierj.edu.br/index.php/Revista/article/view/690/344. Acesso em: 22 jun. 2020.

LESSA, Sérgio. Introdução à filosofia de Marx. São Paulo: Expressão Popular, 2011.

MINAYO, Maria Cecília de Souza. O desafio do conhecimento: pesquisa qualitativa em saúde. 4.ed. São Paulo: Hucitec-Abrasco, 1996. 
MOORE, Michael; KEARSLEY, Greg. Educação a distância: sistemas de aprendizagem online. 3ed. São Paulo: Cengage Learning, 2013.

NETTO, José Paulo. Introdução ao estudo do método de Marx. São Paulo: Expressão Popular, 2011.

NICOLODI, Suzana Cini Freitas. Práticas e processos de mediação pedagógica na EAD. Curitiba: CRV, 2013.

PAIÃO, Ana Laura Franco; PAIÃO, Ivana Célia Franco (2016). Educação a distância e a concepção de seus alunos. EAD em foco, Rio de Janeiro, v.6, n.3, p.1-10, dez. 2013. Disponível em: https://eademfoco.cecierj.edu.br/index.php/Revista/article/view/428/213. Acesso em 22 jun. 2020.

PALLOFF, Rena; PRATT, Keith. O aluno virtual. Porto Alegre: Artmed, 2004.

PALLOFF, Rena M.; PRATT, Keith. Lições da sala de aula virtual: as realidades do ensino on-line. 2. ed. Porto Alegre: Penso Editora, 2015.

PETERS, Otto. Didática do ensino a distância: Experiências e estágio da discussão numa visão internacional. São Leopoldo: Unisino, 2001.

PEREIRA, Geiza Basualdo Bogado. O estudante da EAD (Educação a Distância): um estudo de perfil e interação geracional. Dissertação (Mestrado em Administração) Faculdade de Administração e Economia da Universidade Metodista de São Paulo. São Bernardo do Campo, p.133. 2015.

RICARDO, Jaison Sfogia. Quebrando paradigmas: do preconceito à realidade da Educação Distância. Revista Paidéia _ Revista científica de Educação a Distância, Santos, SP, v. 10, n.18, p. 1-17, jul. 2018. https://periodicosunimes.unimesvirtual.com.br/index.php/paideia/article/view/842 Acesso em 23 mar. 2021.

Recebido em 26/02/2021

Aprovado em 20/04/2021

Revista Devir Educação, Lavras, vol.5, n.1, p.95-111, jan-jun/2021 